\title{
The association of telomere length with paternal history of premature myocardial infarction in the European Atherosclerosis Research Study II
}

\author{
Klelia D. Salpea • Viviane Nicaud • Laurence Tiret • \\ Philippa J. Talmud • Steve E. Humphries • \\ on behalf of the EARS II group
}

Received: 16 November 2007 /Revised: 5 February 2008 / Accepted: 22 February 2008 / Published online: 15 April 2008

(C) Springer-Verlag 2008

\begin{abstract}
Inter-individual variability in telomere length is highly heritable and has been correlated with risk of coronary heart disease (CHD). Our aim was to determine the association of mean leukocyte telomere length with paternal history of premature myocardial infarction (MI). Mean leukocyte telomere length was measured with realtime polymerase chain reactions in 369 male students (1828 years) with a paternal history of MI before the age of 55, recruited from 14 European universities, serving as cases and 396 age-matched controls with no paternal history of CHD. Overall, cases had borderline significantly shorter mean length $(\sim 550 \mathrm{bp})$, adjusted for age and geographical region, than controls $(p=0.05)$. A significant difference in telomere length across the geographical regions of Europe was observed $(p<0.0001)$, with shorter mean length in the Baltic and South and the longest in the Middle. The case-
\end{abstract}

Electronic supplementary material The online version of this article (doi:10.1007/s00109-008-0347-x) contains supplementary material, which is available to authorized users.

K. Salpea $(\bowtie) \cdot$ P. Talmud $\cdot$ S. Humphries

Department of Medicine, Centre for Cardiovascular Genetics,

British Heart Foundation Laboratories, Rayne Building,

Royal Free and University College Medical School,

5 University Street,

London WC1E 6JF, UK

e-mail: k.salpea@ucl.ac.uk

V. Nicaud $\cdot$ L. Tiret

INSERM,

UMR S 525,

Paris \#75634, France

V. Nicaud $\cdot$ L. Tiret

Université Pierre et Marie Curie-Paris 6,

UMR S 525,

Paris \#75634, France

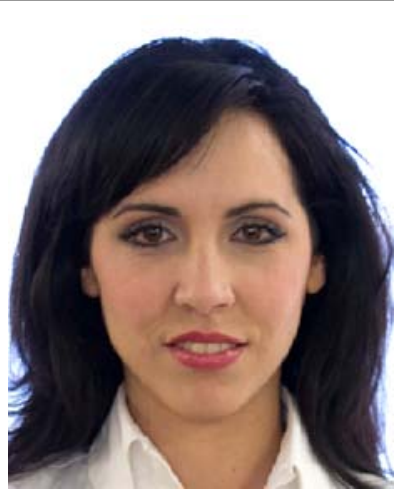

Klelia D. Salpea

received her degree in Biology from the University of Athens, Greece. She is presently a $\mathrm{PhD}$ student in the Department of Medicine, University College London, UK. Her research interests include novel genetic risk factors in cardiovascular disease.

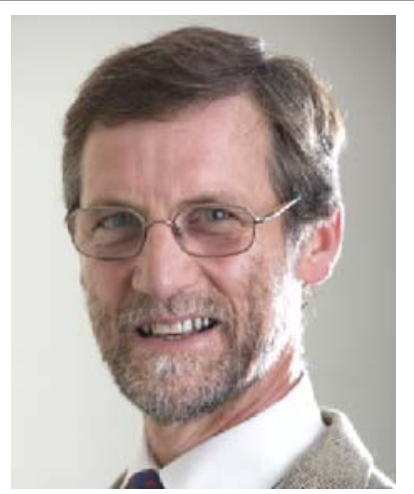

Steve E. Humphries received his $\mathrm{PhD}$ in Biochemistry and Molecular Biology form the University of Glasgow. He is a British Heart Foundation Professor of Cardiovascular Genetics in the Department of Medicine, University College London, UK and CEO of the London IDEAS Genetics Knowledge Park. His research focuses on genetic determinants of CHD traits and the development of DNA tests to identify those at risk of CHD. control difference $(\sim 2.24 \mathrm{~kb})$ in mean length was highly significant only in the Baltic region $(p<0.0001)$. There is suggestive evidence that, in young men, the biological expression of a paternal history of premature $\mathrm{MI}$ is at least in part mediated through inherited short telomeres. The association with paternal history of MI is strongly seen only in the Baltic compared to the rest of Europe, but this is not explained by shorter telomere length in this region. 
Keywords Telomere length $\cdot$ Family history $\cdot$ Premature . Myocardial infarction · Europe

\section{Introduction}

Despite the significant advances in identifying risk factors for coronary heart disease (CHD), these do not completely explain the inter-individual variability related to predisposition for premature disease. Since CHD risk is age-related, there is a need for a marker of biological age in evaluating the risk for early onset of CHD and recent studies have suggested telomere shortening to serve as such $[1,2]$. Telomeres are specialized DNA-protein structures at the end of all chromosomes, which preserve chromosome stability and integrity. In humans they consist of thousand tandem repeats of the TTAGGG sequence [3]. Telomere attrition during mitosis is thought to be a mechanism for cell senescence, which is induced when the mean length reduces below a critical value [4]. Thus telomere length indicates the replicative capacity and biological age of somatic cells [1].

Vascular endothelial and smooth muscle cell senescence and consequent dysfunction are key steps in atherogenesis $[2,5]$. Marked telomere shortening has been detected in senescent vascular cells for human atherosclerotic plaques [6] and there is a growing evidence of an association between telomere length and CHD [7]. Leukocyte mean telomere length (age- and sex-adjusted) of CHD patients was $\sim 300$ base pairs (bp) shorter than that of healthy subjects, and this difference was not accounted for by other CHD risk factors in a study of 203 cases and 180 controls. In the same study, the risk of myocardial infarction (MI) for subjects in the lowest quartile of leukocyte telomere length was $\sim 3$ times higher compared with subjects in the highest quartile [8]. Telomere length evaluation in the prospective West of Scotland Primary Prevention Study (WOSCOPS) with 484 CHD patients and 1,058 controls revealed that individuals in the middle and the lowest tertiles of leukocyte telomere length were at higher risk of developing a CHD event than those in the highest tertile [9]. Telomere attrition may be a primary abnormality that renders the organism more susceptible to CHD. However, reduced leukocyte length in CHD patients may also be a consequence of increased cell turnover induced by chronic inflammatory response underlying atherogenesis [7] or faster shortening due to oxidative stress caused by CHD risk factors [10].

The consistent average length differences between species and chromosome arm differences within species indicate that mean telomere length is genetically determined [11]. Evidence supporting this derives from a twin study showing that $78 \%$ of mean length variability at an individual level is inherited [12] and from linkage studies identifying genetic loci for its determination $[13,14]$. In addition, Graakjaer et al. [15] demonstrated that telomeres retain the characteristic relative length they had at the outset of life towards the end of it and that any length alteration during the lifespan impacts equally on genetically identical chromosomes. This may imply that the observed decrease in telomere length of CHD patients can at least be partly attributed to shorter lengths at birth in those predisposed to premature onset of CHD.

Our hypothesis is that shorter leukocyte telomere length is associated with paternal history of premature MI in individuals of the same age. In the present study we evaluate this association, and whether it is independent of classical risk factors, across Europe.

\section{Materials and methods}

\section{Subjects}

Subjects were participants of European Atherosclerosis Research Study II (EARS II), which was carried out in 1993. Male students between the ages of 18 and 28 years whose fathers had proven MI before the age of 55 (cases, $n=407)$ and age-matched male controls $(n=415)$ were recruited from 14 university student populations from 11 European countries: Tallinn in Estonia (cases/controls, 32/ 36), Helsinki (32/33), and Oulu (23/23) in Finland were designated Baltic; Glasgow (31/31), Belfast (33/33), and Bristol (22/23) were designated United Kingdom (UK); Aarhus in Denmark (30/30), Hamburg in Germany (32/32), Ghent in Belgium (32/32), and Zurich in Switzerland (36/ 36) were designated Middle Europe; Lisbon in Portugal $(18 / 18)$, Reus in Spain (30/33), Naples in Italy (30/30), and Athens in Greece (26/25) were designated South Europe. The subjects were presumed to have been born in the country where they were studying. Details of lifestyle, i.e., smoking, alcohol consumption, medication and physical activity, personal and family medical history, and physiological measurements [i.e., height, weight, blood pressure (BP), and waist and hip circumferences] were established using standardized questionnaires and protocols (Table 1). Body mass index was calculated as weight $/$ height $^{2}$. The study has been approved by ethics committees of collaborating centers and the subjects have given informed consent.

\section{Biochemical measurements}

Blood samples were handled according to specified instructions and were sent to Nancy (France) for storage. They were then dispatched to the different laboratories for 
Table 1 Characteristics at recruitment in cases and controls

\begin{tabular}{|c|c|c|c|}
\hline & Cases $(n=369)$ & Controls $(n=396)$ & $p$ values \\
\hline Age (years) & $22.7(0.1)$ & $22.7(0.1)$ & 0.92 \\
\hline $\operatorname{BMI}\left(\mathrm{kg} / \mathrm{m}^{2}\right)$ & $23.4(0.1)$ & $23.3(0.1)$ & 0.64 \\
\hline Waist/hip ratio & $0.852(0.002)$ & $0.852(0.002)$ & 0.99 \\
\hline SBP (mmHg) & $117.4(0.5)$ & $117.4(0.5)$ & 0.95 \\
\hline DBP $(m m H g)$ & $73.3(0.5)$ & $73.1(0.5)$ & 0.75 \\
\hline Total cholesterol $(\mathrm{mmol} / \mathrm{l})$ & $4.53(0.04)$ & $4.30(0.04)$ & 0.0001 \\
\hline $\mathrm{HDL}(\mathrm{mmol} / \mathrm{l})$ & $1.19(0.01)$ & $1.19(0.01)$ & 0.98 \\
\hline Apo A1 (mg/dl) & $100.1(0.9)$ & $100.7(0.9)$ & 0.61 \\
\hline Apo B (mg/dl) & $73.6(0.9)$ & $69.0(0.8)$ & 0.0002 \\
\hline Apo E (mg/dl) & $2.90(0.05)$ & $2.78(0.05)$ & 0.07 \\
\hline Triglycerides $(\mathrm{mmol} / \mathrm{l})^{\mathrm{a}}$ & $0.91(0.88-0.95)$ & $0.91(0.87-0.94))$ & 0.72 \\
\hline Glucose $(\mathrm{mmol} / \mathrm{l})$ & $5.16(0.02)$ & $5.17(0.02)$ & 0.53 \\
\hline Insulin $(\mathrm{mU} / \mathrm{l})$ & $10.1(0.2)$ & $10.6(0.2)$ & 0.15 \\
\hline Homocysteine $(\mu \mathrm{mol} / 1)^{\mathrm{b}}$ & $10.15(9.82-10.49)$ & $10.31(9.98-10.64)$ & 0.50 \\
\hline Alcohol consumption above median ( $>8 \mathrm{~g} /$ day) $(\%)$ & $46.9 \%$ & $42.2 \%$ & 0.19 \\
\hline Smokers $(\%)$ & $26.4 \%$ & $25.6 \%$ & 0.80 \\
\hline \multicolumn{4}{|l|}{ Physical activity (\%) } \\
\hline Low & $9.9 \%$ & $8.4 \%$ & \multirow{3}{*}{0.78} \\
\hline Moderate & $72.3 \%$ & $76.3 \%$ & \\
\hline Heavy & $14.8 \%$ & $15.3 \%$ & \\
\hline
\end{tabular}

Means (standard error) are adjusted for age and region

$B M I$ Body mass index, $S B P$ systolic blood pressure, $D B P$ diastolic blood pressure, $H D L$ high density lipoprotein, Apo apolipoprotein

${ }^{\mathrm{a}, \mathrm{b}}$ Triglyceride and homocysteine were log-transformed for tests; geometric means $(95 \% \mathrm{CI})$ are presented

specific analyses. The shipment of blood aliquots was done in dry ice. All fasting lipids, apolipoproteins (apo), glucose, and insulin were measured after 12-h overnight fasting. Plasma total cholesterol, high-density lipoprotein (HDL) cholesterol and triglycerides were measured in Glasgow, UK according to the Lipid Research Clinics Manual of Laboratory Operations standardized to the Centres for Disease Control, Atlanta, GA, USA. Lowdensity lipoprotein cholesterol was calculated using the Friedewald formula. The apo A-I, B, and E levels measurement was performed in Brugge, Belgium according to methods previously described [16, 17]. Blood glucose was measured after protein removal by glucose dehydrogenase method and insulin level by radioimmunoassay. The reliability of laboratory performance was assessed by undertaking a repeat blinded analysis of one blood sample in every 20 . The correlation between the repeated measurements was $r>0.95$.

Leukocyte telomere length measurement

Leukocyte DNA, extracted by the salting-out method [18], was available for 774 samples. Telomere length was measured in these DNA samples using a quantitative polymerase chain reaction (PCR)-based method [19]. The relative telomere length was calculated as the ratio of telomere repeats to single-copy gene (SCG) copies (T/S ratio). For each sample the quantity of telomere repeats and the quantity of SCG copies were determined in comparison to a reference sample in a telomere and a SCG quantitative PCR, respectively. All PCRs were performed on the RotorGene 6000 (Corbett Research Ltd, Cambridge, UK).

The raw data from each PCR were analysed using the comparative quantification analysis (Rotor-Gene 6000 software, Corbett Research Ltd, Cambridge, UK). The second derivative of the amplification curve was considered in order to identify the peak of the exponential amplification and determine the Take-Off of the reaction. The TakeOff was estimated by finding the first point to be $80 \%$ below the peak level. Based on the Take-Off point and the amplification, the method calculated the relative quantity of telomere repeats or SCG copies in each sample compared to the reference sample. The same reference DNA was used in all runs to allow comparison of the results in different runs. Every sample was run in duplicate and the mean data were used for the calculations.

The acidic ribosomal phosphoprotein PO (36B4) gene was chosen as SCG. The primers used for the telomere and the SCG amplification were as in Cawthon's report [19] (telomere forward: GGTTTTTGAGGGTGAGGGTGAGG GTGAGGGTGAGGGT/telomere reverse: TCCCGACTAT CCCTATCCCTATCCCTATCCCTATCCCTA) (SCG forward: CAGCAAGTGGGAAGGTGTAATCC/SCG reverse: CCCATTCTATCATCAACGGGTACAA). In the telomere 
PCR, primer concentrations were 135/900 nM (forward/ reverse) and the cycling profile: $95^{\circ} \mathrm{C}$ incubation for $10 \mathrm{~min}$, followed by 22 cycles of $95^{\circ} \mathrm{C}$ for $15 \mathrm{~s}$ and $58^{\circ} \mathrm{C}$ for $120 \mathrm{~s}$. In the SCG PCR, primer concentrations were $300 / 500 \mathrm{nM}$ and the cycling profile: $95^{\circ} \mathrm{C}$ incubation for $10 \mathrm{~min}$, followed by 30 cycles of $95^{\circ} \mathrm{C}$ for $15 \mathrm{~s}$ and $58^{\circ} \mathrm{C}$ for $60 \mathrm{~s}$. For both the telomere and the SCG PCR the final reaction volume was $25 \mu \mathrm{l}$ consisting of $1 \times$ SYBR Green, $1 \times$ qPCR mix $(2 \times$ SensiMix NoRef DNA kit, Quantace, London, UK), $30 \mathrm{ng}$ of template, and the respective primer concentrations. In each run of 32 samples, a reference sample and a no-template control, all in duplicate, were included. The specificity of all amplifications was determined by melting curve analysis. All analyses were processed blinded to case-control status of samples.

A dilution series $(1.25 \mathrm{ng} / \mu \mathrm{l}-160 \mathrm{ng} / \mu \mathrm{l}$, twofold dilution, eight points) was run after optimization for both the telomere and SCG PCRs. For both assays, linearity $\left(R^{2}>0.98\right)$ over this range of input DNA and efficiency over $91 \%$ was observed (web appendix 1 and 2). Nine samples fell outside the range defined by the standard curves and were excluded.

In order to test the reproducibility of the method, 10 randomly chosen samples were run in duplicates on two consecutive days. There was a significant linearity between the measurements obtained on the two different days in linear regression analysis $\left(R^{2}=0.79, p=0.001\right.$, web appendix 3$)$. Moreover, the reproducibility was also assessed with Spearman's non-parametric test of pair-wise correlation that looks at the ranking of each sample. The correlation of the lengths' ranking as measured on the two different days was significant (Spearman coefficient $=0.82, p=0.004$ ). The coefficient of variation of the $\mathrm{T} / \mathrm{S}$ ratios in the repeated measurements of the same sample was 5.6\%.

To validate the assay, 32 DNA samples of subjects aged 24 to 54 years from the Cardiovascular Sciences Department, Leicester University DNA bank were measured in duplicate with the quantitative PCR method in our laboratory. These were then compared to measurements obtained by the conventional terminal restriction fragment (TRF) analysis in Leicester University, as previously described [2]. A significant positive correlation between the telomere length measurements obtained with the two different methods was found by linear regression analysis $\left(R^{2}=0.61, p<0.0001\right.$, web appendix 4). A certain deviation from the length calculated with TRF analysis was expected, since TRF analysis also measures the highly variable subtelomeric region, in contrast to the PCR-based method.

\section{Statistical analysis}

Statistical analysis was performed using the SAS statistical software (version 9.1). The differences in the clinical characteristics between cases and controls were tested by $\mathrm{a} \mathrm{chi}^{2}$ test, for lifestyle factors which were categorical, and by a general linear model adjusted for age and region, for continuous phenotypes. The mean telomere length $(\mathrm{T} / \mathrm{S}$ ratios), triglycerides and homocysteine were not normally distributed (positive skewness), and thus log-transformed data were used for tests and correlations, while geometric means $(95 \%$ CI) are presented in the tables. Differences in telomere length between European regions were tested by a general linear model adjusted for age and case-control status. Differences between cases and controls in telomere length were calculated by a general linear model adjusted for age and region. Homogeneity of the case-control difference across regions was tested by introducing the corresponding interaction term in the general linear model. Partial Pearson's correlation coefficients between telomere length and continuous classical CHD risk factors, calculated separately in cases and controls, were adjusted for age and region. For this purpose, region was introduced as three dummy variates. Homogeneity of the associations in cases and controls was tested by use of a general linear model where the interaction term: "status X telomere length", was introduced. Since all interactions were non-significant, cases and controls were pooled to calculate partial Pearson's correlation coefficients further adjusted for case-control status. The association between telomere length and categorical lifestyle factors (physical activity, alcohol and tobacco consumption) were calculated separately in cases and controls by a general linear model adjusted for age and region. After having verified that there was no interaction between status and categorical factors, cases and controls were pooled to calculate the overall associations further adjusted for case-control status.

\section{Results}

\section{Study cohort}

Leukocyte mean telomere length was successfully determined in 369 cases and 396 controls. The cases and the controls did not differ significantly in any physiological or lifestyle characteristics. Total cholesterol and apo B levels were higher in cases than in controls. No significant differences were found in the other biochemical measurements (Table 1).

\section{Geographical differences}

There was a significant difference in mean telomere length across the geographical regions of Europe after adjustment for age and paternal history of MI $(p<0.0001)$. Shorter 
mean length was found in the Baltic (1.18 [1.08-1.30]) and South $(1.11[1.02-1.21])$ regions and the longest in the Middle of Europe (1.69 [1.56-1.84]) (Table 2, Fig. 1).

\section{Case-control differences}

Overall, cases had borderline significantly shorter mean length than controls after adjusting for age and region (1.30 [1.22-1.39] vs. 1.42 [1.34-1.52], $p=0.05$ ) (Table 2). Using the regression line shown in web appendix 4 , this difference corresponds to $550 \mathrm{bp}$ approximately. When considering each geographical region separately, only in the Baltic mean telomere length was significantly shorter $(\sim 2.24 \mathrm{~kb})$ in cases compared to controls $(0.96$ [0.84-1.09] vs. 1.45 [1.27-1.65], $p<0.0001$ ) (Table 2).

We categorized the length in region-specific quintiles, in order to illustrate the length's distribution and minimize misclassification. It appeared that the greater difference between the percentages of cases and controls was seen in the lowest quintile of length in the Baltic region (Fig. 2).

Association of mean telomere length with classical risk factors and paternal age at birth

Telomere length was not significantly correlated with age ( $r=$ $0.01, p=0.79$ ) and this was probably due to the very narrow age range (18-28 yrs) of the present young cohort. There was a weak but significant positive correlation of telomere length with HDL cholesterol $(r=0.10, p=0.005)$ and glucose $(r=0.21, p=0.0001)$ levels and also weak but significant negative correlation with waist/hip ratio $(r=-0.09, p=0.02)$, apo $\mathrm{B}(r=-0.11, p=0.003)$, apo $\mathrm{E}(r=-0.21, p<0.0001)$, and homocysteine concentration $(r=-0.10, p=0.01)$, after adjustment for age, region and case-control status (Table 3 ). These correlations, apart from the ones with glucose and apo E, were not consistent in cases and controls, although for all of them the test of homogeneity for the effect in cases and controls was not significant. When adjusted for HDL, glucose, waist/hip ratio, apo B, apo E, and homocysteine levels the association between length and case-control status remained highly significant in the Baltic and non-significant in the other regions. The significance in the geographical differences did not change after these adjustments. No significant association of telomere length with smoking, alcohol consumption, or physical activity was found in cases, controls, or the combined cohort (data not shown).

According to previous studies [20], paternal age at birth may have an effect on the child's telomere length. The paternal age at birth was calculated from the age of the offspring and the fathers' age at recruitment in the control group. We found no significant correlation between father's age at birth and child's telomere length $(r=0.02, p=0.08$, Table 3). Such data were insufficient for the cases, since one third of their fathers had already died at the time of recruitment.

\section{Discussion}

In this study, we report a borderline significant association of shorter leukocyte telomere length and paternal history of premature MI in a large multicenter European study and a highly significant association in the Baltic region. Specifically, we found that overall the offspring of premature CHD patients had on average $\sim 550$ bp shorter telomeres than individuals of the same age free of paternal history. This difference is greater than the $\sim 300$ bp difference between coronary artery disease patients and controls of 42-72 years of age, reported by Samani et al. [2], or the $\sim 300$ bp difference between MI patients and controls of 4053 years of age, reported by Brouillete et al. [8]. Although, the effect is of modest statistical significance, it is likely that the true size of the effect is larger when taking into account that the present cohort consists of young healthy men of a very narrow age range (18 to 28 years) having just

Table 2 Geometric mean $(95 \% \mathrm{CI})$ of telomere length (T/S ratio) in cases and control across Europe

\begin{tabular}{lcccc}
\hline & $\begin{array}{l}\text { Mean }(95 \% \mathrm{CI}) \mathrm{T} / \mathrm{S} \text { ratio } \\
\text { in the combined cohort }\end{array}$ & $\begin{array}{l}\text { Mean (95\% CI) T/S } \\
\text { ratio in cases }\end{array}$ & $\begin{array}{l}\text { Mean (95\% CI) T/S } \\
\text { ratio in controls }\end{array}$ & $\begin{array}{l}p \text { value for the } \\
\text { case-control difference }\end{array}$ \\
\hline Overall (369 cases/396 controls) & $1.38(1.31-1.44)$ & $1.30(1.22-1.39)$ & $1.42(1.34-1.52)$ & 0.05 \\
Baltic (85 cases/88 controls) & $1.18(1.08-1.30)$ & $0.96(0.84-1.09)$ & $1.45(1.27-1.65)$ & $<0.0001$ \\
UK (69 cases/81 controls) & $1.55(1.39-1.72)$ & $1.64(1.41-1.91)$ & $1.48(1.29-1.71)$ & 0.27 \\
Middle (121 cases/122 controls) & $1.69(1.56-1.84)$ & $1.68(1.49-1.88)$ & $1.71(1.53-1.92)$ & 0.82 \\
South $(94$ cases/105 controls) & $1.11(1.02-1.21)$ & $1.10(0.97-1.24)$ & $1.13(1.00-1.27)$ & 0.78 \\
\hline
\end{tabular}

Mean T/S ratio for the combined cohort in each region was adjusted for age and paternal history. $p$ value for the difference in mean telomere length across regions, $p<0.0001$. Mean T/S ratio in cases and controls were adjusted for age in each region, and further adjusted for region for the overall results. Tests of homogeneity for the case-control differences among regions, $p<0.001$. 
Fig. 1 Distribution of telomere length in each European region for the combined cohort

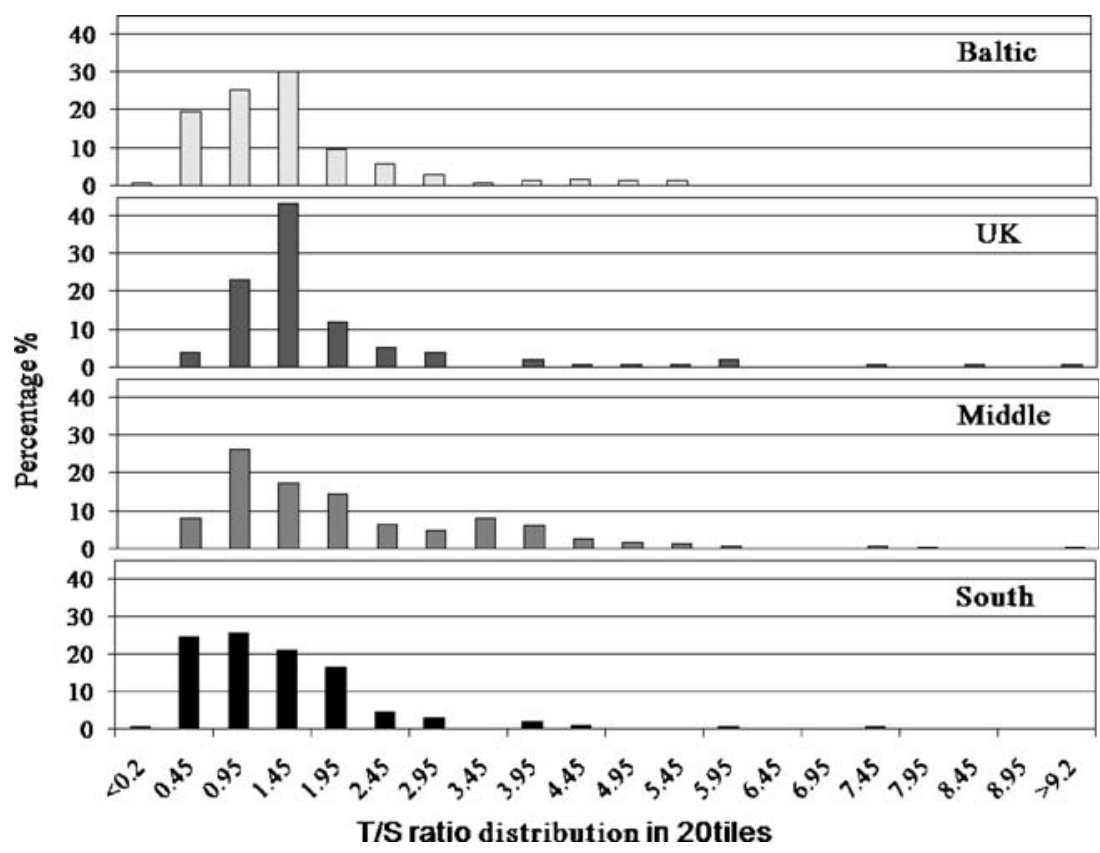

paternal history as discriminator between cases and controls. Moreover, the effect observed here is diluted since only half the genetic information of an offspring is inherited from the CHD prone father with the mother's non-risk telomeres contributing to $50 \%$ of the measured length.
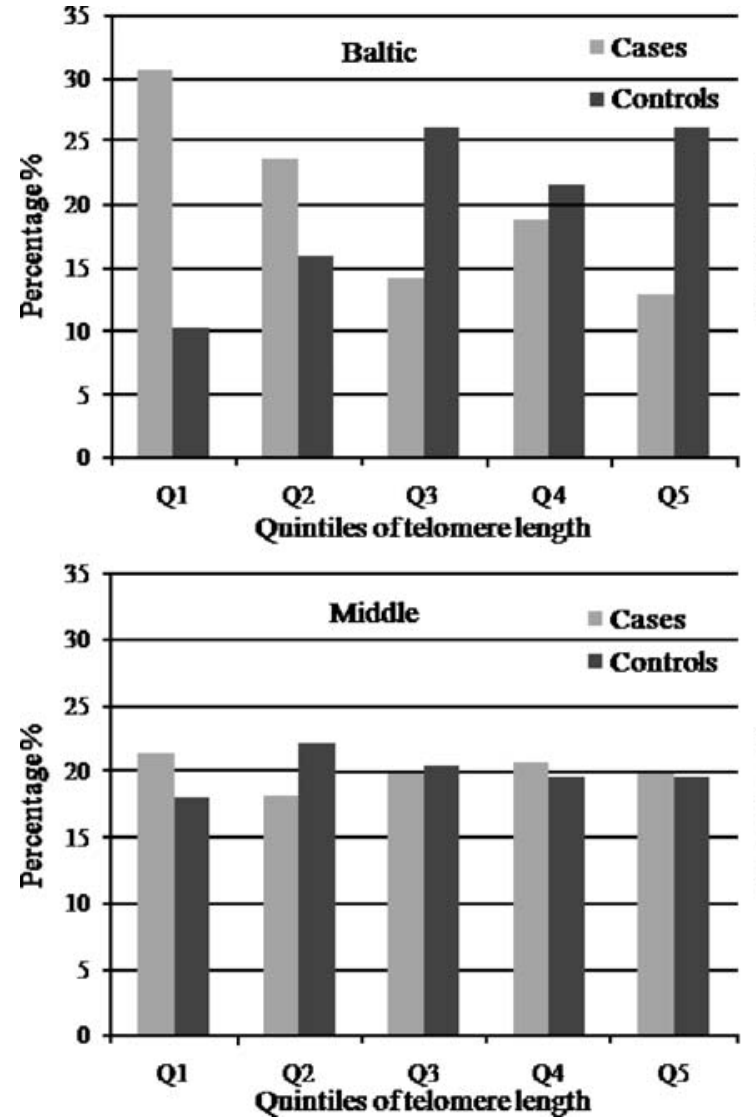

The present data compose the first documentation of a geographical diversity in telomere length across Europe. Students from the Baltic countries and the South of Europe had shorter telomeres ( $7.94 \mathrm{~kb}$ and $\sim 7.62 \mathrm{~kb}$ respectively) while students from the Middle of Europe had the longest
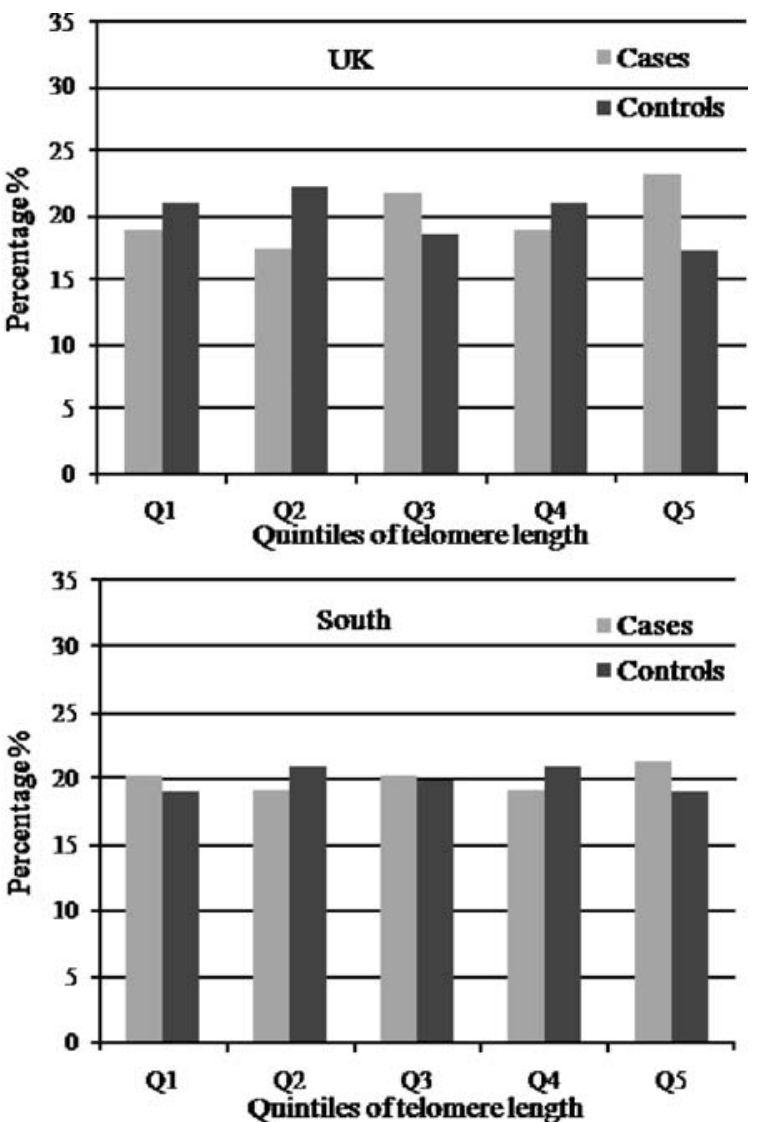

Fig. 2 Distribution of telomere length in each European region for the cases and the controls 
Table 3 Partial Pearson correlation coefficients of telomere length (T/S ratio) with classical risk factors

\begin{tabular}{|c|c|c|c|c|c|c|}
\hline Risk factors & $r$ in cases & $p$ value & $r$ in controls & $p$ value & $r$ in cases and controls pooled & $p$ value \\
\hline Age (yrs) & 0.10 & 0.06 & -0.07 & 0.14 & 0.01 & 0.79 \\
\hline BMI $\left(\mathrm{kg} / \mathrm{m}^{2}\right)$ & -0.12 & 0.02 & -0.02 & 0.69 & -0.07 & 0.05 \\
\hline Waist/hip ratio & -0.08 & 0.12 & -0.11 & 0.04 & -0.09 & 0.02 \\
\hline SBP (mmHg) & 0.09 & 0.11 & 0.04 & 0.45 & 0.06 & 0.12 \\
\hline DBP (mmHg) & -0.03 & 0.60 & -0.03 & 0.59 & -0.04 & 0.30 \\
\hline Total cholesterol (mmol/l) & -0.07 & 0.17 & -0.04 & 0.48 & -0.05 & 0.19 \\
\hline LDL cholesterol (mmol/l) & -0.10 & 0.07 & -0.05 & 0.34 & -0.07 & 0.07 \\
\hline HDL cholesterol (mmol/1) & 0.16 & 0.003 & 0.05 & 0.30 & 0.10 & 0.005 \\
\hline Apo B (mg/dl) & -0.15 & 0.004 & -0.08 & 0.13 & -0.11 & 0.003 \\
\hline Apo A1 (mg/dl) & 0.06 & 0.23 & 0.03 & 0.55 & 0.05 & 0.15 \\
\hline Apo E (mg/dl) & -0.22 & $<0.0001$ & -0.21 & $<0.0001$ & -0.21 & $<0.0001$ \\
\hline Triglycerides $(\mathrm{mmol} / \mathrm{l})$ & -0.08 & 0.16 & -0.03 & 0.62 & -0.05 & 0.19 \\
\hline Glucose $(\mathrm{mmol} / \mathrm{l})$ & 0.26 & $<0.0001$ & 0.18 & 0.0004 & 0.21 & $<0.0001$ \\
\hline Insulin $(\mathrm{mU} / \mathrm{l})$ & -0.07 & 0.17 & 0.06 & 0.29 & -0.02 & 0.66 \\
\hline Homocysteine $(\mu \mathrm{mol} / \mathrm{l})$ & -0.15 & 0.007 & -0.04 & 0.40 & -0.10 & 0.01 \\
\hline
\end{tabular}

Pearson partial correlation coefficient $r$ was adjusted for age and region and further adjusted for case-control status when cases and controls are pooled. Tests of homogeneity of the association of telomere length with waist/hip ratio, HDL cholesterol, apo B, apo E, glucose and homocysteine between cases and controls were non-significant.

$B M I$ Body mass index, $S B P$ systolic blood pressure, $D B P$ diastolic blood pressure, $H D L$ high density lipoprotein, $A p o$ apolipoprotein, $L D L$ lowdensity lipoprotein

( $\sim 10.28 \mathrm{~kb})$. The association of the length with paternal MI history also displayed a geographical diversity. Young men from the Baltic countries whose fathers suffered an early MI had $\sim 2.24 \mathrm{~kb}$ shorter telomeres than men of the same age free of paternal history. This difference was highly significant, while this was not the case for the other regions. The strong association seen in the Baltic can not be attributed to particularly short mean length in that region, since the length was as short in the South, but rather to greater differences between cases and controls. A possible explanation of this discrepancy could be that the Baltic population differs genetically from the rest of Europeans. In support of this, the frequency of various genetic polymorphisms (e.g., PPAR $\gamma$ Pro12Ala, MTHFR C677T, lipoprotein lipase gene (LPL) HindIII, LPL S447X) is also different in the Baltic compared to the rest of Europe [21-23].

Family history of premature CHD is a well-established independent risk factor for CHD [24, 25]. This study was undertaken to determine to what extent telomere length contributes to the family history-associated risk and its relationship with other risk factors. Data from other studies suggest an accelerated telomere shortening related to obesity, smoking and presence of type 1 and 2 diabetes, probably mediated through the increased oxidative stress caused by these factors [26-28]. In addition, pulse pressure and pulse wave velocity have been associated with shorter length [29]. Of the clinical, biochemical, and lifestyle risk factors measured, HDL cholesterol and glucose were positively correlated with the length, while waist/hip ratio, apo B, apo E, and homocysteine displayed a negative correlation. Though, all the correlations were weak and apart from glucose and apo E, not consistent in cases and controls. The correlation of apo E levels with telomere length has not been observed before, and despite being weak could account in part for the geographical diversity seen in length, since its levels differ across the European regions. However, the apo E levels display an increasing north-to-south gradient, while the length was as short in the Baltic as in the South of Europe. Homocysteine on the other hand, also exhibits regional differences and has been found to increase the amount of telomere length lost per population doubling in endothelial cells through a redoxdependent pathway [30]. However, its levels were highest in the South [22] which again is not in accordance with the geographical differences seen in telomere length.

The young age of this cohort may be the reason for the risk factors not to have exerted a large effect on telomere length. This implies that at this early age the interindividual differences in length are more likely to be genetically than environmentally determined. More importantly, the association of short telomeres and paternal history did not change appreciably after adjusting for waist/hip ratio, HDL, apo $\mathrm{B}$, apo $\mathrm{E}$, glucose, and homocysteine levels, indicating that it is not mediated by them. Nevertheless, while the environment may not yet have affected telomere length in the young offspring, it could have played a role in the fathers' early CHD onset. This might explain the strong association of short length with paternal history of early CHD seen in the Baltic and not in the rest of Europe. Another factor which was shown 
in previous studies [20] to have an effect on the offspring telomere length is paternal age at birth. No such association was observed in this study even though the paternal age range was relatively wide ( $31 \pm 12 \mathrm{yrs})$.

So far, the influence of CHD paternal history in the EARS I and II studies was mainly expressed in terms of differences in biochemical measurements (i.e., fasting or postprandial triglycerides, total cholesterol and apo B levels) [31-33]. Here, we show a potential biomarker attributing to the family history-related risk independently of biochemical or lifestyle factors. In addition, most candidate gene studies with the EARS II sample, apart from the HindIII and S447X variants in the lipoprotein lipase gene, found no differences in genotype frequencies between cases and controls [21-23, 31]. Thus, telomere length offers a novel insight into the genetic basis of family history, constituting a possible inherited and early expressed risk factor for CHD.

In vivo experiments have shown a progressive telomere shortening in vascular regions susceptible to atherosclerosis [34], while in vitro experiments have provided data for the contribution of endothelial cell senescence, induced by telomere shortening, in atherogenesis [6]. This suggests a plausible mechanism for the role of telomere shortening as a primary abnormality in the development of CHD. Atherosclerosis is also accompanied by systemic inflammation and thus marked increased cell turnover, which results in shorter leukocyte telomere length [7]. This offers another possible explanation for the short telomere length in leukocytes of individuals prone to CHD. However, the outcome of the present study, coupled with that of twin studies showing that epigenetic/environmental effects on length are relatively minor during life [15], support the theory that in individuals born with relatively short telomeres, vascular cells will reach senescence faster and they will develop atherosclerosis in an earlier age than others.

Limitations of our study need to be considered. The possibility that an unmeasured factor such as inflammation could account for the observed association of telomere length with paternal history of MI cannot be excluded. Although other studies have used leukocyte DNA to examine the relationship of telomere length with CHD risk $[2,8,9]$, telomeres display tissue-specific lengths and rates of loss, so it is not firmly established whether interindividual differences seen in leukocyte telomere length apply to other cell types and especially the vascular tissue. However it is clear that, in comparison to other persons, these who exhibit relatively short or long length in one type of a proliferative somatic cell, respectively express relatively short or long telomeres in other somatic cells [35]. A possibility of a certain degree of degradation due to storage of the leukocyte DNA for a long period of time should be considered, although telomeres are rather stable complexes of GC-rich double stranded DNA and should maintain their structure when diluted DNA is frozen. The evaluation of telomere length in leukocyte DNA samples stored for as long has been previously preformed in the WOSCOP study [9]. The telomere sizes reported there were lower in average than that in EARS II, as would be expected due to the different mean age of the study cohorts and validation of the assay between these two studies allows the comparison to be made.

To summarize, the data suggest that, in young men, the biological expression of a paternal history of premature CHD primarily in the Baltic is at least in part mediated through inherited short telomeres, independently of the risk factors examined in this study. Whether telomere length is only serving as a biomarker of CHD risk, or if it has a functional basis remains to be determined. Results from large prospective studies with follow-up measurements of telomere length will have the possibility to ascertain if individuals with a genetic tendency to relatively short telomeres in leukocytes are at higher risk for developing premature CHD independently of conventional risk factors.

Acknowledgements We thank Professor Nilesh Samani and Dr Scott Brouilette for their valuable help in validating the real time PCR-based method of leukocyte telomere length measurement. This work was supported by the British Heart Foundation [KDS (FS/06/053) and SEH (RG2005/014)] and by the EC Concerted Action BMH1 CT92-0206.

\section{Appendix}

EARS II Project Leader: D. St. J. O'Reilly, UK.EARS II Project Management Group: F. Cambien, France, G. De Backer, Belgium, D. St. J. O'Reilly, UK, M. Rosseneu, Belgium, J. Shepherd, UK, L. Tiret, France.The EARS II Group Collaborating Centres and their Associated Investigators:Austria: H. J. Menzel, Institute for Medical Biology and Genetics, University of Innsbruck, laboratory.Belgium: G. De Backer, S. De Henauw, Department of Public Health, University of Ghent, recruitment centre.Belgium: M. Rosseneu, Laboratorium voor Lipoproteïne Chemie/ Vakgroep Biochemie, University of Ghent, laboratory. Denmark: O. Faergeman, C. Gerdes, Medical Department I, Aarhus Amtssygehus, Aarhus, recruitment centre.Estonia: M. Saava, K. Aasvee, Department of Nutrition and Metabolism, Estonian Institute of Cardiology, Tallinn, recruitment centre.Finland: C. Ehnholm*, R. Elovainio**, J. Peräsalo, *National Public Health Institute, **The Finnish Student Health Service, Helsinki, recruitment centre.Finland: Y.A. Kesäniemi*, M.J. Savolainen*, P. Palomaa**, *Department of Internal Medicine and Biocenter, Oulu, **The Finnish Student Health Service, 
University of Oulu, recruitment centre.France: L. Tiret, V. Nicaud, O. Poirier, INSERM U525, Paris, EARS data centre, laboratory.France: S. Visvikis, Centre de Médecine Préventive, Nancy, laboratory.France: J. C. Fruchart, J. Dallongeville, Service de Recherche sur les Lipoprotéines et l'Athérosclérose (SERLIA), INSERM U325, Institut Pasteur, Lille, laboratory.Germany: U. Beisiegel, C. Dingler, Medizinische Klinik Universitäts-Krankenhaus Eppendorf, Hamburg, recruitment centre and laboratory.Greece: G. Tsitouris, N. Papageorgakis, G. Kolovou, Department of Cardiology, Evangelismos Hospital, Athens, recruitment centre.Italy: E. Farinaro, Dept. of Medical Preventive Sciences, University "Frederico II" of Naples, recruitment centre.The Netherlands: L. M. Havekes, IVVO-TNO Health Research, Gaubius Institute, Leiden, laboratory.Portugal: M. J. Halpern, J. Canena, Instituto Superior de Ciencas da Saude, Lisbon, recruitment centre.Spain: L. Masana, J. Ribalta, A. Jammoul, A. LaVille, Unitat Recerca Lipids, University Rovira i Virgili, Reus, recruitment centre and laboratory.Switzerland: F. Gutzwiller, B. Martin, Institute of Social and Preventive Medicine, University of Zurich, recruitment centre and laboratory.United Kingdom: D. St J. O'Reilly, M. Murphy, Institute of Biochemistry, Royal Infirmary, Glasgow, recruitment centre and laboratory. United Kingdom: S.E. Humphries, P.J. Talmud, V. Gudnason, R.M. Fisher, University College London School of Medicine, London, laboratory.United Kingdom: D. Stansbie, A. P. Day, M. Edgar, Department of Chemical Pathology, Royal Infirmary, Bristol, recruitment centre and laboratory. United Kingdom: F. Kee*, A. Evans**, *Northern Health and Social Services Board, **Department of Epidemiology and Public Health, the Queen's University of Belfast, Belfast, recruitment centre.

\section{References}

1. Vaziri H, Dragowska W, Allsopp RC, Thomas TE, Harley CB, Lansdorp PM (1994) Evidence for a mitotic clock in human hematopoietic stem cells: loss of telomeric DNA with age. Proc Natl Acad Sci U S A 91:9857-9860

2. Samani NJ, Boultby R, Butler R, Thompson JR, Goodall AH (2001) Telomere shortening in atherosclerosis. Lancet 358:472473

3. Blackburn EH (1991) Structure and function of telomeres. Nature 350:569-573

4. Allsopp RC, Harley CB (1995) Evidence for a critical telomere length in senescent human fibroblasts. Exp Cell Res 219:130-136

5. Minamino $T$, Miyauchi $\mathrm{H}$, Yoshida $\mathrm{T}$, Ishida $\mathrm{Y}$, Yoshida $\mathrm{H}$, Komuro I (2002) Endothelial cell senescence in human atherosclerosis: role of telomere in endothelial dysfunction. Circulation 105:1541-1544

6. Matthews C, Gorenne I, Scott S, Figg N, Kirkpatrick P, Ritchie A, Goddard M, Bennett M (2006) Vascular smooth muscle cells undergo telomere-based senescence in human atherosclerosis: effects of telomerase and oxidative stress. Circ Res 99:156-164
7. Serrano AL, Andres V (2004) Telomeres and cardiovascular disease: does size matter? Circ Res 94:575-584

8. Brouilette S, Singh RK, Thompson JR, Goodall AH, Samani NJ (2003) White cell telomere length and risk of premature myocardial infarction. Arterioscler Thromb Vasc Biol 23:842846

9. Brouilette SW, Moore JS, McMahon AD, Thompson JR, Ford I, Shepherd J, Packard CJ, Samani NJ (2007) Telomere length, risk of coronary heart disease, and statin treatment in the West of Scotland Primary Prevention Study: a nested case-control study. Lancet 369:107-114

10. Aviv A (2002) Telomeres, sex, reactive oxygen species, and human cardiovascular aging. J Mol Med 80:689-695

11. de Pauw ES, Roelofs H, Zwinderman A, van Houwelingen JC, Fibbe WE, de Knijff P, Pearson PL, Tanke HJ (2005) Studying the biological and technical sources of variation in telomere length of individual chromosomes. Cytometry A 65:35-39

12. Slagboom PE, Droog S, Boomsma DI (1994) Genetic determination of telomere size in humans: a twin study of three age groups. Am J Hum Genet 55:876-882

13. Vasa-Nicotera $M$, Brouilette $S$, Mangino $M$, Thompson JR, Braund P, Clemitson JR, Mason A, Bodycote CL, Raleigh SM, Louis E, Samani NJ (2005) Mapping of a major locus that determines telomere length in humans. Am J Hum Genet 76:147151

14. Andrew T, Aviv A, Falchi M, Surdulescu GL, Gardner JP, Lu X, Kimura M, Kato BS, Valdes AM, Spector TD (2006) Mapping genetic loci that determine leukocyte telomere length in a large sample of unselected female sibling pairs. Am J Hum Genet 78:480-486

15. Graakjaer J, Pascoe L, Der-Sarkissian H, Thomas G, Kolvraa S, Christensen K, Londono-Vallejo JA (2004) The relative lengths of individual telomeres are defined in the zygote and strictly maintained during life. Aging Cell 3:97-102

16. Siedel J, Schiefer S, Rosseneu M, Bergeaud R, De Keersgieter W, Pautz B, Vinaimont N, Ziegenhorn J (1988) Immunoturbidimetric method for routine determinations of apolipoproteins A-I, A-II, and B in normo- and hyperlipemic sera compared with immunonephelometry. Clin Chem 34:1821-1825

17. Bury J, Vercaemst R, Rosseneu M, Belpaire F (1986) Apolipoprotein $\mathrm{E}$ quantified by enzyme-linked immunosorbent assay. Clin Chem 32:265-270

18. Bolla MK, Haddad L, Humphries SE, Winder AF, Day IN (1995) High-throughput method for determination of apolipoprotein $\mathrm{E}$ genotypes with use of restriction digestion analysis by microplate array diagonal gel electrophoresis. Clin Chem 41:1599-1604

19. Cawthon RM (2002) Telomere measurement by quantitative PCR. Nucleic Acids Res 30:e47

20. De Meyer T, Rietzschel ER, De Buyzere ML, De Bacquer D, Van Criekinge W, De Backer GG, Gillebert TC, Van Oostveldt P, Bekaert S (2007) Paternal age at birth is an important determinant of offspring telomere length. Hum Mol Genet 16:3097-3102

21. Poirier O, Nicaud V, Cambien F, Tiret L (2000) The Pro12Ala polymorphism in the peroxisome proliferator-activated receptor gamma2 gene is not associated with postprandial responses to glucose or fat tolerance tests in young healthy subjects: the European Atherosclerosis Research Study II. J Mol Med 78:346351

22. Gudnason V, Stansbie D, Scott J, Bowron A, Nicaud V, Humphries S (1998) C677T (thermolabile alanine/valine) polymorphism in methylenetetrahydrofolate reductase (MTHFR): its frequency and impact on plasma homocysteine concentration in different European populations. EARS group. Atherosclerosis 136:347-354

23. Humphries SE, Nicaud V, Margalef J, Tiret L, Talmud PJ (1998) Lipoprotein lipase gene variation is associated with a paternal 
history of premature coronary artery disease and fasting and postprandial plasma triglycerides: the European Atherosclerosis Research Study (EARS). Arterioscler Thromb Vasc Biol 18:526-534

24. Barrett-Connor E, Khaw K (1984) Family history of heart attack as an independent predictor of death due to cardiovascular disease. Circulation 69:1065-1069

25. Myers RH, Kiely DK, Cupples LA, Kannel WB (1990) Parental history is an independent risk factor for coronary artery disease: the Framingham Study. Am Heart J 120:963-969

26. Jeanclos E, Krolewski A, Skurnick J, Kimura M, Aviv H, Warram JH, Aviv A (1998) Shortened telomere length in white blood cells of patients with IDDM. Diabetes 47:482-486

27. Sampson MJ, Winterbone MS, Hughes JC, Dozio N, Hughes DA (2006) Monocyte telomere shortening and oxidative DNA damage in type 2 diabetes. Diabetes Care 29:283-289

28. Valdes AM, Andrew T, Gardner JP, Kimura M, Oelsner E, Cherkas LF, Aviv A, Spector TD (2005) Obesity, cigarette smoking, and telomere length in women. Lancet 366:662-664

29. Benetos A, Okuda K, Lajemi M, Kimura M, Thomas F, Skurnick J, Labat C, Bean K, Aviv A (2001) Telomere length as an indicator of biological aging: the gender effect and relation with pulse pressure and pulse wave velocity. Hypertension 37:381-385

30. Xu D, Neville R, Finkel T (2000) Homocysteine accelerates endothelial cell senescence. FEBS Lett 470:20-24
31. De Backer G, De Henauw S, Sans S, Nicaud V, Masana L, Visvikis S, Gerdes C, Wilhelmsen L (1999) A comparison of lifestyle, genetic, bioclinical and biochemical variables of offspring with and without family histories of premature coronary heart disease: the experience of the European Atherosclerosis Research Studies. J Cardiovasc Risk 6:183-188

32. Rosseneu M, Fruchart JC, Bard JM, Nicaud V, Vinaimont N, Cambien F, De Backer G (1994) Plasma apolipoprotein concentrations in young adults with a parental history of premature coronary heart disease and in control subjects.. The EARS Study. European Atherosclerosis Research Study. Circulation 89:19671973

33. Tiret L, Gerdes C, Murphy MJ, Dallongeville J, Nicaud V, O'Reilly DS, Beisiegel U, De Backer G (2000) Postprandial response to a fat tolerance test in young adults with a paternal history of premature coronary heart disease - the EARS II study (European Atherosclerosis Research Study). Eur J Clin Invest 30:578-585

34. Chang E, Harley CB (1995) Telomere length and replicative aging in human vascular tissues. Proc Natl Acad Sci U S A 92:11190 11194

35. Martens UM, Zijlmans JM, Poon SS, Dragowska W, Yui J, Chavez EA, Ward RK, Lansdorp PM (1998) Short telomeres on human chromosome $17 \mathrm{p}$. Nat Genet 18:76-80 